\title{
Analysis of body weight of adults by different indirect methods
}

\section{Análise da massa corporal de adultos por diferentes métodos indiretos}

\author{
Melina Gadagnotto Cezaroni ${ }^{1}$ \\ (D) https://orcid.org/0000-0003-0172-2307 \\ Leonardo Breda ${ }^{1}$ \\ (D) https://orcid.org/0000-0002-0855-8864 \\ Gabriel Keine Kuga ${ }^{2}$ \\ (D) https://orcid.org/0000-0002-2404-0686 \\ Rafael Calais Gaspar ${ }^{3}$ \\ (D) https://orcid.org/0000-0002-2208-3527 \\ Vitor Rosetto Muñoz \\ (D) https://orcid.org/0000-0003-4280-6558 \\ Thaís Dantis Pereira de Campos ${ }^{3}$ \\ (D) https://orcid.org/0000-0002-9426-874X \\ Raphael dos Santos Canciglieri ${ }^{3}$ \\ (D) https://orcid.org/0000-0001-7974-1757 \\ José Rodrigo Pauli3 \\ (D) https://orcid.org/0000-0002-6129-1521 \\ Paulo Henrique Canciglieri ${ }^{1}$ \\ (D) https://orcid.org/0000-0003-4116-870X
}

Abstract - Anthropometry is considered a widely applicable and effective method to track adiposity. Among the current methods of anthropometric analysis are the Body Mass Index (BMI) and the Waist Hip Index (ICQ) are utilized. However, both presents limitations because they fail to estimate the adiposity. In this sense, recently the Body Adiposity Index (IAC) emerged as an important tool in the adipose mass evaluation of large populations. Thus, the present study aimed to evaluate adults aged between 18 and 50 years through BMI, IAC and ICQ and to analyze the agreement degree between the methods. A total of 2602 individuals were analyzed, of which 1457 were women and 1145 men. After analyzing the data, it was verified that the majority of the population are within the standards of men was classified as not overweight only for ICQ and women for BMI and ICQ. In contrast the population of men is classified as healthy only for ICQ and women for BMI and ICQ. Concerning the agreement between the methods, only a positive and significant agreement between BMI and IAC was observed. Therefore, it can be concluded that IAC is an alternative for assessing body composition, showing a good method to estimate the percentage of total body fat of men and women, thus increasing the possibilities of diagnosis of obesity and overweight.

Key words: Anthropometry; Health; Obesity.

Resumo - A antropometria é considerada um método aplicável e eficaz para rastrear a adiposidade. Dentre os métodos atuais estão o indice de Massa Corpórea (IMC) e Indice Cintura Quadril (ICQ). Entretanto, ambos apresentam limitaçôes por não estimarem adiposidade. Recentemente o Índice de Adiposidade Corporal (IAC) surgiu como uma importante ferramenta na avaliação da massa adiposa de grandes populaçôes. Assim, o presente estudo teve como objetivo avaliar adultos com idade entre 18 e 50 anos através do IMC, IAC e ICQ e analisar o grau de concordância entre os métodos. Analisou-se 2602 indivíduos dos quais 1457 eram mulheres e 1145 homens. Verificou-se que a população de homens foi classificada como sem excesso de peso apenas para o ICQ e as mulheres para o IMC e ICQ. Em contrapartida a população de homens encontra-se classificada como saudável apenas para o ICQ e as mulheres para o IMC e ICQ. Somente foi observada uma positiva e significante concordância entre - IMC e LAC. Portanto, pode-se concluir que o IAC é uma alternativa para avaliação da composição corporal, se mostrando um bom método para estimar o percentual de gordura corporal total de homens e mulheres na faixa etária de 18 a 50 anos, ampliando-se dessa forma as possibilidades de avaliação do perfil antropométrico e diagnóstico de sobrepeso e obesidade.

Palavras-chave: Antropometria; Obesidade; Saúde.
1 Fundação Hermínio Ometto. Araras, SP. Brasil.

2 Universidade Estadual Paulista. Programa de Pós-Graduação em Ciências da Motricidade. Rio Claro, SP. Brasil.

3 Universidade Estadual de Campinas. Faculdade de Ciências Aplicadas. Laboratório de Biologia Molecular do Exercício. Limeira, SP. Brasil.

Received: December 07, 2018 Accepted: April 10, 2020

How to cite this article Cezaroni MG, Breda L, Kuga GK, Gaspar RC, Muñoz VR, Campos TDP, Canciglieri RS, Pauli JR, Canciglieri PH. Analysis of body weight of adults by different indirect methods. Rev Bras Cineantropom Desempenho Hum 2020, 22:e60591. DOI: http://dx.doi.org/10.1590/19800037.2020v22e60591

Copyright: This work is licensed under a Creative Commons Attribution 4.0 International License. 


\section{INTRODUCTION}

Obesity is a global public health issue ${ }^{1}$. The current obesity epidemic is related to the urbanization process, sedentary lifestyle, high-calorie diet, and alcohol and tobacco consumption ${ }^{1,2}$. On the other hand, anthropometry is considered to be the most useful, inexpensive and non-invasive method for tracking obesity, and is universally applicable in large populations ${ }^{3}$. Among the main methods of anthropometric analysis are the Body Mass Index (BMI), Waist Hip Index (ICQ) and Body Adiposity Index (IAC).

The BMI is a low cost, fast, easy to apply and feasible method for treating large populations. However, BMI has limitations in determining body adiposity in athletes, individuals with a high percentage of lean body mass, children, the elderly and people of different ethnicities ${ }^{4}$.On the other hand, ICQ is another widely used method because it has low cost and easy application $^{5}$. ICQ $\geq 1.0$ for men and ICQ $\geq 0.80$ for women indicate high cardiometabolic risk ${ }^{6}$ and sudden death ${ }^{7}$. However, the ICQ does not allow estimating the percentage of body adiposity.

Therefore, due to the limitations of those methods, the Body Adiposity Index (ICQ) was proposed in 2011 as a method for evaluating the excess body fat for large populations ${ }^{8}$. A previous study was conducted to determine the adiposity of individuals through an equation that is easy to apply, with less time spent and that presents more reliable results than BMI and $\mathrm{ICQ}^{8}$. The IAC was developed to simplify the estimation of fat mass and, therefore, it was based on the DEXA (dual-energy X-ray absorptiometry) where IAC equals hip circumference measurement divided by height measurement, times the square root of height and result subtracted $18^{8}$.

It is possible that there is a difference between BMI, IAC and ICQ for the screening of overweight in large populations and little is known about the agreement between the methods. Thus, the present study aimed to investigate the body composition of adults in the city of Araras, state of São Paulo, through different anthropometric methods and to evaluate if there is an agreement between them.

\section{METHOD \\ Participants}

The analyzes were performed after approval of the procedures by the Ethics and Scientific Merit Committee of the HermínioOmetto University Center(UNIARARAS) under number 64158517.6.0000.5385, following the Brazilian legislation for human studies and in accordance with the principles contained in the Declaration of Helsinki of the Association World Physician (2000).

This research was conducted with individuals living in the city of Araras-SP and region. Data were obtained over a five-year period (20112016) in 2602 individuals aged 18 to 59 years and they were evaluated at the HermínioOmetto University Center. Exclusion criteria were individuals who performed a physical exercise on the day of evaluation and/or individuals who trained three or more times during the week. 


\section{Anthropometric assessments}

The participants' body mass was measured using a Filizola ${ }^{\circledR}$ scale (São Paulo, Brazil). Height measured using Sanny ${ }^{\circledR}$ wall stadiometer (São Bernardo do Campo, Brazil). Waist circumference (2 fingers above the umbilical scar) and hip circumference (point of highest glute ratio/groin inlet height / femoral trochanter height) were also measured with a nonelastic Sanny ${ }^{\circledR}$ tape (São Bernardo Campo, Brazil) to within 1 millimeter.

The BMI was calculated by dividing body mass (kilograms) by squared height (meters): body mass $(\mathrm{kg}) /$ height $(\mathrm{m}) 2{ }^{4}$.The ICQ was calculated by dividing waist circumference by measuring hip circumference: waist circumference $(\mathrm{cm}) /$ hip circumference $(\mathrm{cm})^{5}$. And the IAC was calculated from measurements of height and hip circumference measurements, and no measurement of body mass was required: hip circumference $(\mathrm{cm}) /$ height $(\mathrm{m}) 1,5^{9}$.

\section{Statistical Analysis}

The normality of the sample was verified by the Lilliefors test. The UMann Whitney test for two independent samples was used for comparison between groups, considering the distribution by gender (men and women) and age (young adults and middle-aged adults), followed by the analysis of the kappa index ${ }^{10}$. The data were expressed as mean \pm SD and the Student's t-test was performed. Analysis of variance (ANOVA), followed by Bonferroni post-hoc test. The significance level was set at 0.05. The GraphPad Prism 5.0 software was used to perform the analyses.

\section{RESULTS}

The Lilliefors test of normality demonstrated that the sample distribution
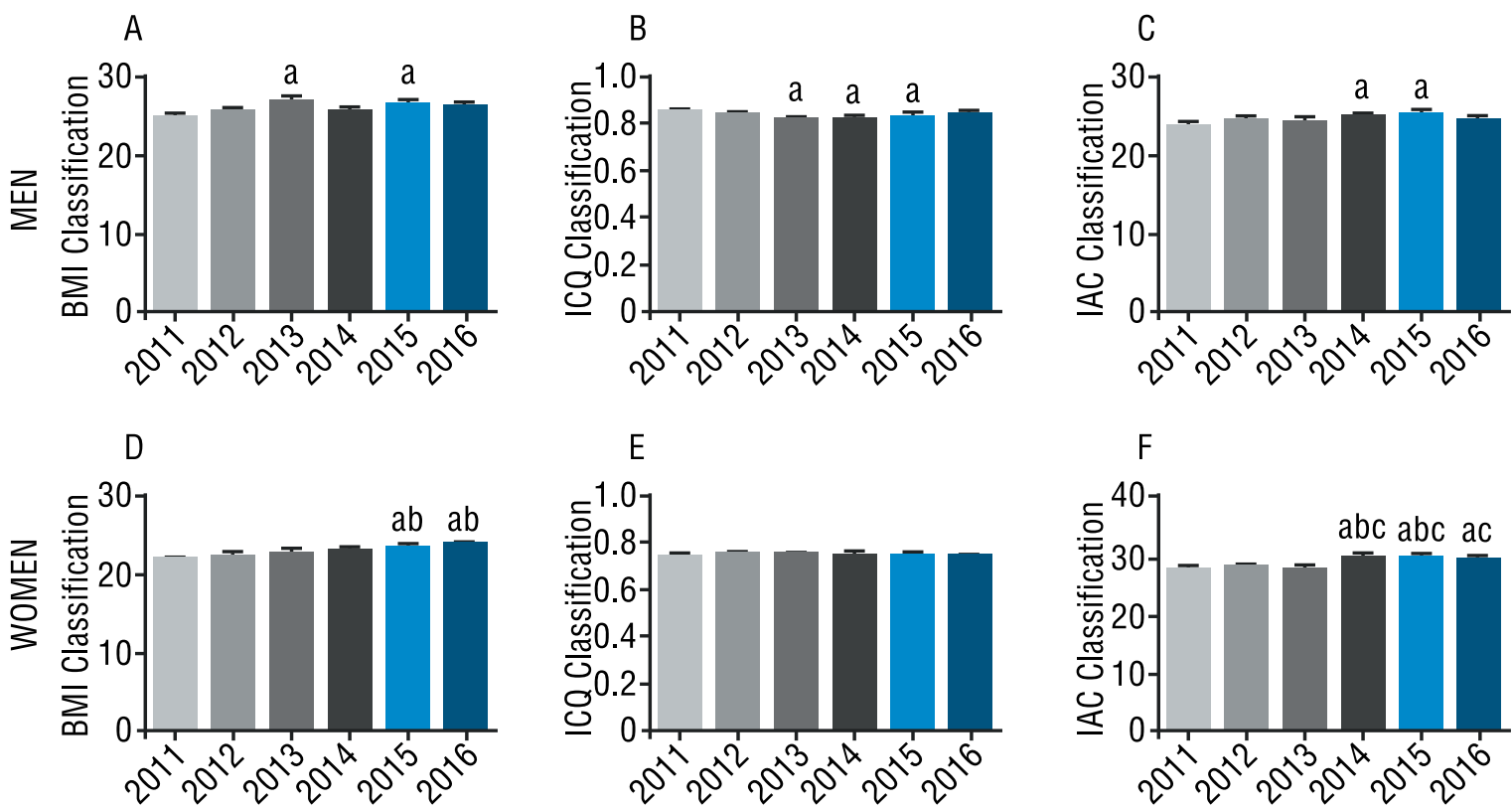

a, $p<0.05$ vs $2011 \quad$ b, $p<0.05$ vs $2012 \quad$ c, $p<0.05$ vs 2013

Figure 1. Anthropometric values obtained from 2011 to 2016. Assessments of male participants for BMI (A), ICQ (B) and IAC (C). Assessments of female participants for BMI (D), ICQ (E) and IAC (F). 
of 2602 individuals selected and divided between 1457 females and 1145 males. Data follow non-normal distribution.

When the BMI and IAC data were crossed, the kappa index revealed a satisfactory agreement $(0.5522)$ for both men (0.5816) and women (0.5169) (Table 1). When the BMI and ICQ data were crossed, the kappa index revealed poor agreement (0.2902) for men (0.2684) and women (0.3418) (Table 2). After cross-checking the IAC and ICQ data, the kappa index revealed poor agreement for both the entire study sample (0.1447) and for the men (0.1355) and women (0.1724) (Table 3).

Table 1 - 2x2 contingency table with the total study sample, classified as "no overweight" and "overweight" by BMI and IAC.

\begin{tabular}{|c|c|c|c|c|}
\hline & & \multicolumn{3}{|c|}{ Body Mass Index (BMI) } \\
\hline & & Not overweight & Overweight & Total \\
\hline \multirow{15}{*}{$\begin{array}{l}\text { Body Adiposity } \\
\text { Index(IAC) }\end{array}$} & & \multicolumn{3}{|c|}{ Every sample } \\
\hline & Not overweight & 1361 & 111 & 1472 \\
\hline & Overweight & 442 & 688 & 1130 \\
\hline & Total & 1803 & 799 & 2602 \\
\hline & Kappa index: 0.5522 & & & \\
\hline & & \multicolumn{3}{|c|}{ Men } \\
\hline & Not overweight & 529 & 72 & 601 \\
\hline & Overweight & 165 & 379 & 544 \\
\hline & Total & 694 & 451 & 1145 \\
\hline & Kappa index: 0.5816 & & & \\
\hline & & \multicolumn{3}{|c|}{ Mulheres } \\
\hline & Not overweight & 832 & 39 & 871 \\
\hline & Overweight & 277 & 309 & 586 \\
\hline & Total & 1109 & 348 & 1457 \\
\hline & Kappa index: 0.5169 & & & \\
\hline
\end{tabular}

Table 2 - 2x2 contingency table with the total study sample, classified as "no overweight" and "overweight" by BMI and ICQ.

\begin{tabular}{|c|c|c|c|c|}
\hline & & \multicolumn{3}{|c|}{ Body Mass Index (BMI) } \\
\hline & & Not overweight & Overweight & Total \\
\hline \multirow{15}{*}{$\begin{array}{l}\text { Waist } \\
\text { Hip Index } \\
\text { (ICQ) }\end{array}$} & & \multicolumn{3}{|c|}{ Toda amostra } \\
\hline & Not overweight & 1497 & 450 & 1947 \\
\hline & Overweight & 299 & 356 & 655 \\
\hline & Total & 1796 & 806 & 2602 \\
\hline & Kappa index: 0.2902 & & & \\
\hline & & \multicolumn{3}{|c|}{ Homens } \\
\hline & Not overweight & 640 & 308 & 948 \\
\hline & Overweight & 53 & 144 & 197 \\
\hline & Total & 693 & 452 & 1145 \\
\hline & Kappa index: 0.2684 & & & \\
\hline & & \multicolumn{3}{|c|}{ Mulheres } \\
\hline & Not overweight & 857 & 142 & 999 \\
\hline & Overweight & 246 & 212 & 458 \\
\hline & Total & 1103 & 354 & 1457 \\
\hline & Kappa index: 0.3418 & & & \\
\hline
\end{tabular}


Table 3. $2 \times 2$ contingency table with the total study sample, classified as "no overweight" and "overweight" by IAC and ICQ.

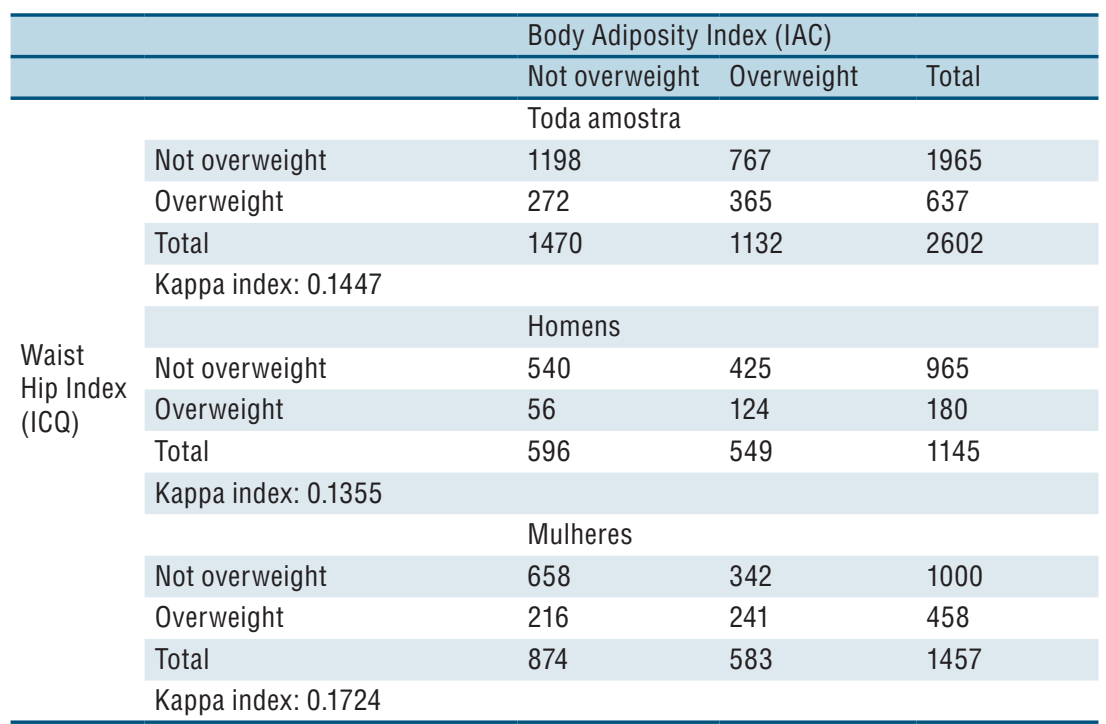

\section{DISCUSSION}

This study aimed to investigate the body composition of adults from the city of Araras - São Paulo through BMI, IAC, and ICQ and to evaluate if there is an agreement between them. Through BMI analyses, it was possible to observe an increase in 2013 and 2015 compared to 2011 in men's assessments and an increase in 2015 and 2016 compared to 2011 in women's assessments. In addition, the average BMI of men and women is reaching the considered overweight range, corroborating the current perspective of increased prevalence of obesity ${ }^{11}$.

The results obtained through the ICQ evaluation show that the female gender did not present a statistical difference between the years. Regarding the male gender, there was a reduction in 2013, 2014 and 2015 compared to 2011. The ICQ was indicated as an anthropometric measure capable of predicting the risk of myocardial infarction, which was not possible through $\mathrm{BMI}^{12}$. An interesting study was conducted in 2005 with 27,000 participants from 52 countries highlighting the high number of people at risk for myocardial infarction through the ICQ assessment, and this risk was underestimated through the BMI assessment. However, the ICQ has some limitations because hip circumference varies widely among people of different ethnicities ${ }^{13}$.Moreover, in the present study, we found poor agreement between BMI and ICQ. Corroborating with the present research, in Salvador (BA), a study of 634 individuals of both sexes with 316 adults aged between 20 and 59 years and 318 elderly aged over 60 years, also showed a low-intensity agreement between BMI and the $\mathrm{ICQ}^{14}$.Current evidences indicate that ICQ is effective at predicting the risk of cardiovascular events, but $\mathrm{BMI}$ is more efficient at characterizing obesity than $\mathrm{ICQ}^{15}$.

Through the IAC analysis, it was possible to observe an increase in women's values in 2014, 2015 and 2016. Regarding men, the 2014 and 
2015 evaluations presented higher values than in 2011. The population of the city of Araras tends to present higher ACI values over the years, which has been pointed as an interesting index to estimate body adiposity. The $\mathrm{ACI}$ has the advantage over BMI since individuals with high lean mass are not classified as obese as with $\mathrm{BMI}^{4}$.

Like the present study, in the city of Viçosa (MG) a study was conducted with the participation of 972 individuals, aged between 20 and 59 years, in order to analyze the validity and associated factors of body adiposity index in adults ${ }^{9}$. Therefore, the researchers demonstrated for the first time the association between the prevalence of adiposity, as assessed by the IAC, and socioeconomic and behavioral factors'.

Due to its applicability advantages compared to more complex and costly methods such as DEXA, we found in the present study that IAC can be a good alternative to estimate body fat in the absence of more accurate techniques, especially in population-based studies because it showed good agreement with BMI for both men and women. In addition, it was shown that the IAC has a strong correlation with DEXA, on the other hand, the BMI did not show the same degree of correlation with this gold standard technique for body composition evaluation ${ }^{8}$.

Concerning the agreement between the methods, our study found a strong agreement between the IAC and the BMI. Similarly, a previous study with aged 19-49 years men and women showed good agreement between $\mathrm{BMI}$ and $\mathrm{AI}$, a strong correlation between BMI and body composition $(r=0.81, p<0.001)$ and efficacy in identifying body fat ${ }^{16}$.

Regarding the applied methods, the ACI seems to be a viable method, easily applicable and with good agreement with BMI in adults. This method appears to be more reliable on evaluating adults when compared to BMI since does not take into account the body composition of the individual ${ }^{4,9}$. The IAC was efficient in exposing the results in anthropometric analysis aiming to diagnose overweight and obesity in large populations. New studies comparing IAC, BMI, and ICQ with other methods considered gold standard for the analysis of body composition in large populations may enrich and complement the findings of this work. Therefore, the IAC is an important index for body mass assessment, since it has a strong correlation with BMI. The IAC is able to overcome the limitations presented by other indices for obesity and excess adiposity screening large populations.

\section{CONCLUSION}

The present study was able to verify that the young adult population (men and women) are healthy for the three methods studied. In contrast, the population of middle-aged men is classified as healthy only for ICQ and women for BMI and ICQ.

The agreement between the methods, no significant difference was found between IAC x ICQ and ICQ x BMI methods. Nevertheless, a positive and significant agreement between ACI x BMI was observed. 
For this reason, it is not possible to state which method has the highest agreement and effectiveness in identifying body fat, since only the BMI and IAC methods showed significant agreement with each other.

From the results presented in this paper, we can conclude that, although further studies and validations are needed, the IAC is an alternative for body composition evaluation. It is a good method to estimate the percentage of total body fat of men and women due to its low cost, ease of application and reliability. Therefore expanding the possibilities of diagnosis of obesity and overweight, regardless of the environment or availability of specific materials and equipment.

\section{COMPLIANCE WITH ETHICAL STANDARDS}

\section{Funding}

This research did not receive any specific grant from funding agencies in the public, commercial, or not-for-profit sectors. This study was funded by the authors

\section{Ethical approval}

Ethical approval was obtained by the Ethics Committee for $\mathrm{Hu}-$ man Research, Hermínio Ometto Foundation, protocol number 64158517.6.0000.5385and the protocol was written according to the standards set by the Declaration of Helsinki.

\section{Conflict of interest statement}

The authors have no conflict of interests to declare.

\section{Author Contributions}

Conceived and designed the experiments: PHC. Performed the experiments: MGC. Analyzed the data: MGC, LB. Contributed reagents/materials/analysis tools: PHC. Wrote the paper: MGC, LB, GKK, RCG, VRM, TDPC, RSC, and JRP. All authors read and approved the final version of the manuscript.

\section{REFERENCES}

1. Gluckman PD, Hanson M, Zimmet P, Forrester T. Losing the War Against Obesity: The Need for a Developmental Perspective. Sci Trans1 Med 2011;3(93):19.

2. Malta DC, Silva Jr JB. O Plano de Ações Estratégicas para o Enfrentamento das Doenças Crônicas Não Transmissíveis no Brasil e a definição das metas globais para o enfrentamento dessas doenças até 2025: uma revisão. Epidemiol Serviços Saúde 2013;22(1):151-64.

3. Abrantes MM, Lamounier JA, Colosimo EA. Prevalência de sobrepeso e obesidade em crianças e adolescentes das regiões Sudeste e Nordeste. J Pediatr (Rio J) 2002;78(4):335-40.

4. Buss J. Limitations of Body Mass Index to Assess Body Fat. Workplace Health Saf $2014 ; 62(6): 264-264$.

5. Medeiros RJD, Sousa M, Cantisani GN, Lima ACL, Torres M, Silva JMF, et al. Analise do impacto do ICQ e cc sobre o risco cardíaco em pessoas com baixos níveis de atividade física. Conexões 2008;6(0):184-96. 
6. Acuña K, Cruz T. Avaliação do estado nutricional de adultos e idosos e situação nutricional da população brasileira. Arq Bras Endocrinol Metabol 2004;48(3):345-61.

7. Oliveira Filho A, Shiromoto R. Efeitos do exercício físico regular sobre índices preditores de gordura corporal: índice de massa corporal, relação cintura-quadril e dobras cutâneas. J Phys Educ 2008;12(2):105-12.

8. Bergman RN, Stefanovski D, Buchanan TA, Sumner AE, Reynolds JC, Sebring NG, et al. A Better Index of Body Adiposity. Obesity 2011;19(5):1083-9.

9. Segheto W, Hallal PC, Marins JCB, Silva DCG, Coelho FA, Ribeiro AQ et al. Fatores associados e índice de adiposidade corporal (IAC) em adultos: estudo de base populacional. Cien Saude Colet 2018;23(3):773-83.

10. Landis JR, Koch GG. The measurement of observer agreement for categorical data. Biometrics 1977;33(1):159-74.

11. Wang YC, McPherson K, Marsh T, Gortmaker SL, Brown M. Health and economic burden of the projected obesity trends in the USA and the UK. Lancet 2011;378(9793):815-25.

12. Yusuf S, Hawken S, Ônpuu S, Bautista L, Franzosi MG, Commerford P, et al. Obesity and the risk of myocardial infarction in 27000 participants from 52 countries: a case-control study. Lancet 2005;366(9497):1640-9.

13. Lear SA, James PT, Ko GT, Kumanyika S. Appropriateness of waist circumference and waist-to-hip ratio cutoffs for different ethnic groups. Eur J Clin Nutr 2010;64(1):42-61.

14. Sampaio LR, Figueiredo V. Correlação entre o índice de massa corporal e os indicadores antropométricos de distribuição de gordura corporal em adultos e idosos. Rev Nutr 2005;18(1):53-61.

15. Goyal D, Logie I-M, Nadar SK, Lip GYH, Macfadyen RJ. Generalized Obesity but not that Characterized by Raised Waist-Hip Ratio Is Associated with Increased Perceived Breathlessness During Treadmill Exercise Testing. Cardiovasc Ther 2009;27(1):10-6.

16. Gonçalves R, Mascarenhas LPG, Liebl EC, Lima VA, Souza WB, Grzelczak MT, et al. Grau de concordância do IMC e do IAC com percentual de gordura corporal. Rev Bras Qual Vida 2014;6(1): 8-16.

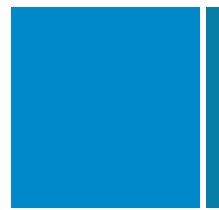

Corresponding author

Paulo Henrique Canciglieri

Doutor Maximiliano Baruto avenue, 500,

Jardim Universitário. Araras - São Paulo, Brazil

Zip postal: 13607-339

E-mail: paulocanciglieri@fho.edu.br 